\title{
How Much Risk Is Mitigated by LTC Protection Schemes? A Methodological Note and a Case Study of the Public System in Spain
}

\author{
Montserrat Guillén ${ }^{\mathrm{a}}$ and Adelina Comas-Herrera ${ }^{\mathrm{b}}$ \\ ${ }^{a}$ Department of Econometrics, Riskcenter-IREA, University of Barcelona, Av. Diagonal, 690, \\ E-08034 Barcelona, Spain. \\ E-mail: mguillen@ub.edu \\ ${ }^{\mathrm{b}}$ PSSRU, LSE Health and Social Care London School of Economics and Political Science, Houghton Street, \\ London WC2A 2AE, U.K. \\ E-mail: A.Comas@1se.ac.uk
}

We present a methodology to measure the risk of incurring extremely large individual lifetime costs of long-term care (LTC). We show a method that can be used to compare the risk reductions achieved by alternative LTC protection plans. Our proposed methodology is illustrated with a case study. Our estimates show that, according to our proposed risk measure, the Spanish public LTC system mitigates individual risk by more than 30 per cent compared to the situation where no public protection is available. However, the Spanish public LTC system still leaves individuals facing very high lifetime costs of care. We estimate that there is a risk of about 1 per cent that a man will have to spend more than $€ 211,800$ and a risk of about 1 per cent that a woman will have to spend about $€ 232,600$ to cover lifetime LTC costs. Despite the current public Spanish LTC coverage, risk mitigation may still be too low since catastrophic costs of care persist and, therefore, we suggest that private insurance should be encouraged. The Geneva Papers (2012) 37, 712-724. doi:10.1057/gpp.2012.33

Keywords: social care; ageing; lifetime expenditure; long-term care; risk quantification

Article submitted 8 August 2011; accepted 21 June 2012; published online 8 August 2012

\section{Introduction and motivation}

One of the main objectives of long-term care (LTC) projection schemes, public and private, is to mitigate the risk to individuals of being exposed to "catastrophic" costs of care, ${ }^{1}$ which can occur when a person needs care for a very long period of time. A U.S.-based study suggested that the average value of lifetime LTC expenditures for people turning 65 in 2005 was approximately US\$47,000, with 28 per cent of individuals facing costs in excess of US\$100,000. ${ }^{2}$

Recent estimates of the distribution of lifetime cost of care in England by Fernández and Forder ${ }^{3}$ show that around a third of people aged 65 and over will spend little on

\footnotetext{
${ }^{1}$ See, for example, OECD (2011) and Fernández et al. (2009).

2 Kemper et al. (2005).

${ }^{3}$ Fernández and Forder (2010).
} 
care. However, for a small proportion of people, LTC costs will represent so-called "catastrophic" levels of expenditure: 7 per cent of people aged 65 will face lifetime care costs of at least $£ 100,000$, and 5 per cent of at least $£ 200,000{ }^{4}$ Bolancé et al. ${ }^{5}$ show similar results for the Spanish case and they also point at significant differences between men and women. Women's LTC average expenditure from age 65 to death is much higher than men's, and extreme cases are more frequent.

The effectiveness of LTC protection schemes in terms of their ability to protect people from catastrophic costs, that is, as risk mitigation instruments, has received little attention in the literature. Risk mitigation, when addressing economic losses, usually works by transferring the risk to someone else, who would cover the cost if the loss occurs in exchange of a payment (or premium). Zuchandke et al. ${ }^{6}$ discussed the impact of the introduction of social LTC insurance in Germany on financial security assessment, but they did not measure risk mitigation. Risk transfer is easily achieved by sharing the risk with other individuals who may also suffer the same type of loss. A way to mitigate the risk to an individual of having to spend an enormous amount of money on LTC during his or her lifetime is to be part of an LTC coverage protection scheme that shares the expenditure among participants in the programme. ${ }^{7}$ LTC protection can take many different forms, ranging from contribution to a national public LTC system through general or local taxation, to social insurance contributions, to individual or grouppurchased private insurance. In practice, in most countries public and private LTC coverage protection systems coexist and complement each other to different degrees. ${ }^{8}$

This paper discusses risk measures that are well-known in insurance and financial economics and their potential use for comparing the economic capacity of LTC protection systems as risk transfer instruments. Risk measurement is essentially aimed at evaluating both the likelihood that a loss occurs and the magnitude of this loss. We propose a method to assess how much risk is mitigated by an LTC protection system that would otherwise be borne by individuals or their families. Our quantitative risk measurement relies on basic statistical concepts such as the estimated statistical distribution of lifetime costs of care, which can be obtained by micro-simulation ${ }^{9}$ or by a method based on multiple decrement tables. ${ }^{10}$

Formal definitions of risk measures are available and their mathematical properties have been studied in the context of risk management, actuarial science and finance. ${ }^{11}$ Our contribution is to adapt these measures to the analysis and comparison of LTC protection schemes. In the rest of this paper, our loss random variable is the lifetime cost of LTC.

\footnotetext{
${ }^{4}$ Fernández and Forder (2010, p. 11).

${ }^{5}$ Bolancé et al. $(2010 ; 2012)$.

${ }^{6}$ Zuchandke et al. (2010).

${ }^{7}$ See, for example, Barr (2010) and de Castries (2009).

${ }^{8}$ See, for example, OECD (2011) and Rodrigues and Schmidt (2010).

${ }^{9}$ Fernández and Forder (2011).

${ }^{10}$ Bolancé et al. (2010).

${ }^{11}$ See, for instance, McNeil et al. (2005), Denuit et al. (2005), Coles (2001), Panjer (2006) and Panjer et al. (2008).
} 


\section{Notation and basic concepts}

We denote by $X_{0}$ the lifetime cost of LTC from a given age $t$ to death assuming that there is no level of protection so that the individual has to pay for all the costs of services aimed at his or her care throughout the remaining lifetime. ${ }^{12}$ At age $t$ the value of $X_{0}$ is unknown mainly due to the uncertainty about the probability of needing care, its duration and the inflation of the cost of services. The total lifetime cost spent in LTC will only become known once the person dies. Note that there will also be changes in risk factors and treatments that will have an impact on the evolution of disability rates, ${ }^{13}$ thus prediction of lifetime LTC cost is difficult. We assume that $X_{0}$ is a random variable that follows a probability distribution function $F_{0}(x)$, for $x \geqslant 0$ defined as the probability that the lifetime cost of LTC from age $t$ is not larger than $x$.

We will use subscript $p$ to denote that the individual's lifetime costs of LTC are covered totally or partially by an insurance programme (public or private). Assume $X_{p}$ is the cost of lifetime LTC for an individual at age $t$ if he or she is covered by a public system or subscribes to a voluntary protection plan so that part (or all) of the cost of LTC in $X_{0}$ is covered by an insurance scheme, either private or public or both. Again, and similarly to $X_{0}$, the final value of $X_{p}$ is unknown at age $t$, and it will only become known once the person dies. At age $t, X_{p}$ is a random variable that follows a probability distribution function $F_{p}(x), x \geqslant 0$ which is the probability that the lifetime cost of LTC not covered by the external protection is smaller than $x$.

We aim at quantifying the risk transferred from $X_{0}$ to the protection scheme: that is, from the individual to the insurance plan or the public protection programme (or a combination of both). One simple way to do that is by comparing the distribution of $X_{0}$ and $X_{p}$ or their respective risk measures. We do not explore the decision to purchase LTC insurance protection. Certainly, risk aversion plays a central role in the decision to purchase, as well as wealth, age and personal circumstances. ${ }^{14}$

\section{Risk mitigation of a protection for LTC lifetime individual expenditure}

Using simple risk measures, we can estimate how much an LTC protection scheme will reduce the economic loss for those facing the highest lifetime costs of care (often referred to as catastrophic costs). The simplest risk measure that can be applied in our context is Value-at-Risk. Let us fix a probability level $\alpha_{0}, \alpha_{0} \in(0,1)$. When using Value-at-Risk we are estimating the minimum lifetime cost of LTC that is incurred by the $\alpha_{0}$-th proportion of the population that spends more money on

\footnotetext{
12 The kind of costs considered in this variable are exclusively care costs, that is, service delivery. LTC provision has been extensively studied in the specialised literature and a consensus exists on the fact that care needs depend on the level of disability. We only consider payments related to assistance at home, support from a third person to perform daily life activities, the cost of day care or the cost of residential care. We explicitly exclude sanitary costs or hotel costs, such as meals. Our approach is compatible with similar studies such as Fernández and Forder (2010) for the U.K.

${ }^{13}$ See, for example, Jagger et al. (2006).

${ }^{14}$ See Pauly (1990) and Zhou-Richter et al. (2010).
} 
LTC. ${ }^{15,16}$ The information provided by Value-at-Risk can be useful for insurance companies, especially for the premium calculation of private and supplementary LTC insurance. $^{17}$

We will define the performance of protection policy $p$ in terms of risk mitigation, ${ }^{18}$ with respect to the scenario where the whole burden is on the individual. Based on the concept of Value-at-Risk we define the first risk mitigation measure as the difference between Value-at-Risk without and with an insurance protection coverage:

$$
R M_{1}\left(\alpha_{0} ; 0 ; p\right)=\operatorname{VaR}_{\alpha_{0}}\left(X_{0}\right)-\operatorname{VaR}_{\alpha_{0}}\left(X_{p}\right)
$$

The main drawback of $R M_{1}\left(\alpha_{0} ; 0 ; p\right)$ is that there must be a consensus on which is the $\alpha_{0}$ level (or quantile level) that is going to be chosen for comparative purposes. Once $\alpha_{0}$ is fixed, $R M_{1}\left(\alpha_{0} ; 0 ; p\right)$ can be computed for several protection alternatives in order to rank them.

We may consider the concept of Tail-Value-at-Risk, which is useful to measure the average values at risk for all cases above a quantile level. Let us assume that $\alpha_{0}$, $\alpha_{0} \in(0,1)$ is a fixed confidence level. We would like to examine all Value-at-Risk at levels between $a_{0}$ and 1 .

The Tail-Value-at-Risk can be interpreted as an average for all Value-at-Risk cases above a level $\alpha_{0}$. We are particularly interested in the expected value of lifetime LTC costs with no protection $\left(X_{0}\right)$ or with protection $\left(X_{p}\right)$ for the $\left(1 \alpha_{0}\right) 100$ per cent group of individuals aged $t$ who will experience costs larger than $\operatorname{VaR}_{\alpha_{0}}\left(X_{j}\right)$, for $j=0$ or $j=p$, respectively. This measure concentrates on the average cost for the group that will incur larger costs.

Note that there are many possible ways to fix the value of $\alpha_{0}$. For instance, choosing $\alpha_{0}=75$ per cent, then $T V a R_{\alpha_{0}}\left(X_{j}\right)$ for $j=0$ or $j=p$, respectively, corresponds to the average cost incurred by the group that exceeds the 75 per cent percentile cost. Alternatively, the value of $\alpha_{0}$ can be defined indirectly. For example, let us assume that we define $\alpha_{0}$ as the level at which $F_{0}\left(x_{0}\right)=\alpha_{0}$ given that $x_{0}$ is a fixed amount (e.g. the yearly minimum wage). In this case $\left(1-\alpha_{0}\right) 100$ per cent is defined as the percentage of individuals aged $t$ that would face lifetime LTC costs above minimum wage. The value of $x_{0}$ could be fixed, for example with respect to a yearly minimum income level. It could also be fixed in absolute terms. Then $T V a R_{\alpha_{0}}\left(X_{0}\right)$ would be interpreted as the

${ }^{15}$ See Jorion (2007).

${ }^{16}$ The notion Value-at-Risk with level $\alpha_{0}\left(\alpha_{0}\right.$-quantile) of individual lifetime LTC cost under protection scheme, $j=0$ or $j=p$ means that there is a $\left(1-\alpha_{0}\right)$ proportion of the population aged $t$ that spends at least $\operatorname{VaR}_{\alpha_{0}}\left(X_{0}\right)$ if there is no protection and at least $\operatorname{VaR}_{\alpha_{0}}\left(X_{p}\right)$ if protection $p$ covers him or her. Another way to interpret Value-at-Risk is that an $\alpha_{0}$ proportion of the population aged $t$ spends during the rest of his or her lifetime less than $\operatorname{VaR}_{\alpha_{0}}\left(X_{0}\right)$ if there is no protection, and less than $\operatorname{VaR}_{\alpha_{0}}\left(X_{p}\right)$ under protection p. Value-at-Risk has been widely used for assessing financial risk (Jorion, 2001, Klüppelberg et al., 1999). Note that $\alpha_{0}$ is often called the confidence level, whereas $\left(1-\alpha_{0}\right)$ is known as the risk level.

${ }^{17}$ We thank the reviewer for pointing out this fact. We also note that private insurance products may consider coverage up to a maximum accumulated compensation amount.

18 This should not be confused with the notion of risk margin in another context (see Floreani, 2011), which refers to capital loading. 
average lifetime LTC cost incurred by those who would face a lifetime LTC cost greater than the minimum wage.

Note that if $\alpha_{0}=0$, Tail-Value-at-Risk is simply the expected lifetime LTC cost, on average, of all individuals in the population.

We will define the amount of risk mitigation of protection $p$ with respect to the absence of protection $R M_{2}\left(\alpha_{0} ; 0 ; p\right)$, using the concept of Tail-Value-at-Risk as:

$$
R M_{2}\left(\alpha_{0} ; 0 ; p\right)=T V a R_{\alpha_{0}}\left(X_{0}\right)-T V a R_{\alpha_{0}}\left(X_{p}\right)
$$

In order to compute $R M_{2}\left(\alpha_{0} ; 0 ; p\right)$ first we need to choose a level for $\alpha_{0}$. Once $a_{0}$ is fixed, $R M_{2}\left(\alpha_{0} ; 0 ; p\right)$ can be calculated for several protection alternatives $p$ (or combinations of protection schemes) and one can compare alternatives with respect to the gain in risk mitigation.

The main limitation of the capacity of $R M_{2}\left(\alpha_{0} ; 0 ; p\right)$ in terms of its use to compare alternative $p$ policies is that the comparison is made for those facing the highest cost only. However, calculating $R M_{2}\left(\alpha_{0} ; 0 ; p\right)$ is simple, once estimates of the distribution functions of $X_{0}$ and $X_{p}$ are available. Moreover, $R M_{2}\left(\alpha_{0} ; 0 ; p\right)$ can be interpreted as the average LTC cost that is covered by the protection scheme for those individuals that incur the highest (or catastrophic) costs.

It is interesting to note that $T V a R_{\alpha_{0}}\left(X_{j}\right)$ at a given level is a coherent risk measure that has been used in many areas. It has risen independently in a variety of fields and has been given names such as Conditional Value-at-risk, Conditional Tail Expectation or Expected Shortfall. ${ }^{19}$ It satisfies the so-called axioms of coherence, namely translation invariance, subadditivity, positive homogeneity and monotonicity.

\section{Using Tail-Value-at-Risk to rank risk mitigation}

Here we define the relative risk mitigation index, $R M_{3}$, which measures to what extent an LTC protection scheme reduces the average lifetime cost of care for those incurring the highest costs, relative to a baseline scenario where no coverage is available.

Let us assume that $X_{0}$ is the reference cost baseline distribution. We can define a percentage reduction of the Tail-Value-at-Risk at level $\alpha_{0}$, which we call the relative risk mitigation index as:

$$
R M_{3}\left(\alpha_{0} ; 0 ; p\right)=\left(1-\frac{T \operatorname{VaR} \alpha_{\alpha_{0}}\left(X_{p}\right)}{\operatorname{TVaR}_{\alpha_{0}}\left(X_{0}\right)}\right) \cdot 100 .
$$

Assuming that costs incurred are always positive and that $X_{p} \leqslant X_{0}$ with almost certainty in probability terms, which means that the probability that $X_{p}$ is larger than $X_{0}$ is 0 , then it can be shown that $R M_{3}\left(\alpha_{0} ; 0 ; p\right)$ is a score between 0 and 100 .

A difficulty in the comparison between $X_{0}$ and $X_{p}$ is that there is no guarantee that the probability of $X_{0}$ equals 0 is the same as the probability that $X_{p}$ equals 0 .

\footnotetext{
${ }^{19}$ See Duffie and Pan (1997), Artzner et al. (1999) and Denuit et al. (2005).
} 
Individuals may incur cost if there is no protection programme, while they may have to pay nothing when $p$ is implemented. The procedure can be extended to compare more than one possible protection scheme.

\section{Estimating LTC cost distribution}

We carried out a simulation of a cohort of 1,000,000 individuals for each gender, using information on death probabilities and prevalence to estimate the LTC cost distribution, assuming smooth transitions between states. We use period life tables because it is easier to gain access to them. Nevertheless, such life tables represent the current mortality situation (based on the respective year). In a dynamic setting, it is more appropriate to use cohort life tables because the use of period life tables would lead to biased results. The same is true for the probabilities of becoming dependent on care. In our simplified approach, we assume an initial population of size $N$ aged $t$. To determine on a yearly basis what will be an individual's need of care, that is, the level of dependence severity, we assume that individuals can only remain in the initial severity level, they may deteriorate or die. There are five possible states: Active, Degree 1, Degree 2, Degree 3 or Dead. We assume that individuals cannot recover. This is restrictive but it seems a plausible assumption for elderly individuals and for the very strong scale of dependence used in our case. The calculation process is as follows:

- Step 1: We assign a proportional number of individuals from the initial population to all possible states except death. We will keep track of the evolution of every single individual in this simulated cohort.

- Step 2: Using the probability of death corresponding to the age and gender of each individual, we update the numbers of people in each state after one year. We assume that individuals die and therefore the number of individuals in every state decreases. We track the trajectory of every single individual in the cohort with respect to their state.

- Step 3: With the individuals who have survived up to the next age, the distribution of individuals among the different severity levels is recomposed using the assumptions of no possible recovery. Transitions between states are tracked. In our transitions, we give priority to transitions to the nearest possible state admitting more individuals.

Steps 2 and 3 are iterated until the maximum age is reached or until no more individuals have survived.

Once the process is completed we consider the trajectory for each individual and compute the accumulated cost incurred, assuming that an active individual does not need care. We use average yearly cost of care provided to each severity level using a national average. Life tables, that is, probability of death by age and sex, are obtained from the National Statistical Institute and prevalences of severity level are also collected from the National Statistical Institute.

A histogram of the previous accumulated costs for all individuals in the simulated cohort provides an estimate of the random distribution of lifetime LTC costs from the initial age. This distribution estimation method is easy to implement as computation is fast. 


\section{A case study: The public LTC system in Spain}

We apply the Risk Mitigation measures discussed above in order to measure the degree to which the Spanish public LTC system mitigates the risk of catastrophic costs of care.

In December 2006, the Spanish parliament approved the Law of Dependence, which was enforced in 2007. The law established a public LTC system and granted new rights to citizens in need of personal assistance. The law was conceived as a fourth pillar to the Spanish welfare system. Since then, the Spanish general budget has assigned funds for citizens needing LTC, and those funds have been set independently of public health funds.

The new Spanish Law of Dependence established an entitlement to public LTC in case of dependence. The system is universal and funded by taxes. Entitlements are based on the severity of dependence and not on the individual's wealth and income. The Spanish regulation establishes a score that varies as a function of the intensity of care needed. The score is a number between 0 and 100 . There are three severity levels in the Spanish LTC evaluation system. A person is eligible if they are assessed to belonging to one of these three dependency severity groups: Degree 1, if support is needed once a day (Level I: 25-40 points, Level II: 40-49 points), Degree 2, if assistance is to be provided two or three times per day (Level I: 50-64 points, Level II: 65-74 points) and Degree 3, if assistance is demanded several times during the day (Level I: 75-89 points, Level II: $90+$ points). Once an individual becomes eligible, he or she receives a personalised plan and can choose between assistance in kind or in cash, if he or she prefers to be cared at home and this is indeed possible. Not all degrees and levels of severity are funded. Currently, only those assessed as having severity of dependence consistent with Degree 2 or Degree 3 are eligible to obtain an allocation from the public system. It is likely that budget restrictions will hinder the full implementation of the public system protection to all severity levels. It is often argued that the categorisation of dependence severity entails some level of moral hazard. Maximum monthly allocations for individuals as a function of care needed for 2009 are shown in Table 1.

Table 1 indicates that someone who is eligible to receive LTC support from the public system can obtain up to $€ 833.96$ in cash as a monthly payment for the services received or $€ 520.69$ monthly for family care, if he prefers that relatives take care of him. In that case, an extra sum of $€ 162.49$ is given monthly to cover the social security

Table 1 LTC subsidy in Spain in 2009, monthly maximum (minimum) allocation in euros

\begin{tabular}{lcccc}
\hline Degree of dependence & Level of dependence & Service & Family care $^{\mathrm{b}}$ & Personal assistant $^{\text {Pan }}$ \\
\hline 3 & II & $833.96(266.57)$ & 520.69 & 833.96 \\
3 & I & $625.47(181.26)$ & 416.98 & 625.47 \\
2 & II & $462.18(103.20)$ & 337.25 & \\
2 & I & $401.20(70.70)$ & 300.90 & \\
\hline
\end{tabular}

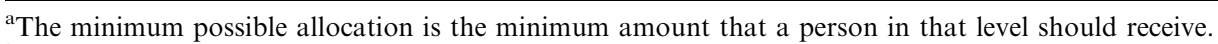

${ }^{\mathrm{b}}$ An extra allocation of $€ 162.49$ is assigned for training and social security contributions of the carer. 
taxes, and the training and education of the person who is nominated as the family caregiver. The maximum public support allowance is gradually lowered depending on the severity level of dependence. Currently, the minimum possible allowance is $€ 70.70$ monthly for people with a severity Degree 2, at Level I. We should note that once a person is placed into one of the above categories (except for the highest level), if there are signs of deterioration, he or she can apply again to be reclassified.

In 2010 , there were 614,750 people receiving some form of service or allocation. It is possible for people to receive more than one benefit. Seven thousand four hundred and sixty-eight people got a prevention plan; 74,775 got tele-assistance; care at home was supplied to 78,968; care at day or night centre units was assigned to 39,312 users; residential care was provided to 114,263; supplementary service allocation was given to 50,803 people and supplementary cash allocation for family care was given to 357,599 Spanish citizens. Cash benefits for family care are by far the most popular form of support from the public system.

Note that benefits only cover part of the costs of care, not the full cost. For instance, the cost of a care home for a dependent person is higher than the maximum possible allocation for the most severe level of dependence. Therefore individuals or their families need to cover the rest of the costs of care using their own income or wealth.

Bolancé et al. ${ }^{10}$ estimated the distribution function ${ }^{20}$ of lifetime LTC cost for men aged 65. A large survey by the Spanish Statistical Institute carried out in 2008 was used to produce the estimate. Respondents were classified as eligible or non-eligible by matching survey respondents to the levels of need that would trigger entitlement to public benefits. They were also rated on the official scale levels of severity. Based on that work, we also simulated a cohort of men and a cohort of women and compared the distribution of lifetime LTC costs if no public entitlements were available and the distribution of lifetime LTC costs if the entitlements that are established by the Spanish regulation were applied, so that cost would be partially covered by the state. The estimation is done by using the simple simulation procedure described in the methods section and using data from the Spanish period life tables published by the Spanish Statistical Institute, the prevalence of dependence by gender and age estimated from the survey, standard assumptions on the transitions from active to disabled conditions, and the yearly cost of care depending on the severity level based on a Spanish average cost of service published by the Ministry of Social Affairs. The yearly cost of care for an individual in the lowest severity level (Degree 1) is on average $€ 13,917$, in Degree 2 the yearly cost is on average $€ 12,512$. Note that the cost is slightly lower for Degree 2 than for Degree 1 because day care in nursing homes is cheaper than intensive care at home used for Degree 1. In Degree 3, the yearly average cost of care is $€ 17,296$. A standard discount rate could have been incorporated in the simulation assuming, for instance, a 2 per cent yearly cost inflation. The estimation of the distribution function is calculated easily using the empirical distribution function obtained from the simulation process, that is, the percentage of cases that incurred less

\footnotetext{
${ }^{20}$ Our approach can be applied to any starting point age $t$. However, our discussion is focused on age 65 , which is the current retirement age. Individuals needing LTC before age 65 are usually people whose need for support has been caused by factors other than the natural ageing process.
} 
720

than each given level of cost. The distribution function of lifetime LTC costs is presented in Figure 1, where the $x$-axis is the percentile level and the $y$-axis represents the Value-at-Risk.

Table 2 presents the Value-at-Risk and the Tail-Value-at-Risk for three levels $\alpha_{0}$ which are equal to 90 per cent, 95 per cent and 99 per cent and which correspond respectively to risk levels equal to 10 per cent, 5 per cent and 1 per cent for the distribution of lifetime LTC cost of those aged 65 in 2008 in Spain. Two possibilities are considered: the estimated lifetime LTC cost distribution if individuals pay for all the services, that is, without any public system coverage, and the distribution when the current public system covers some of the LTC cost.

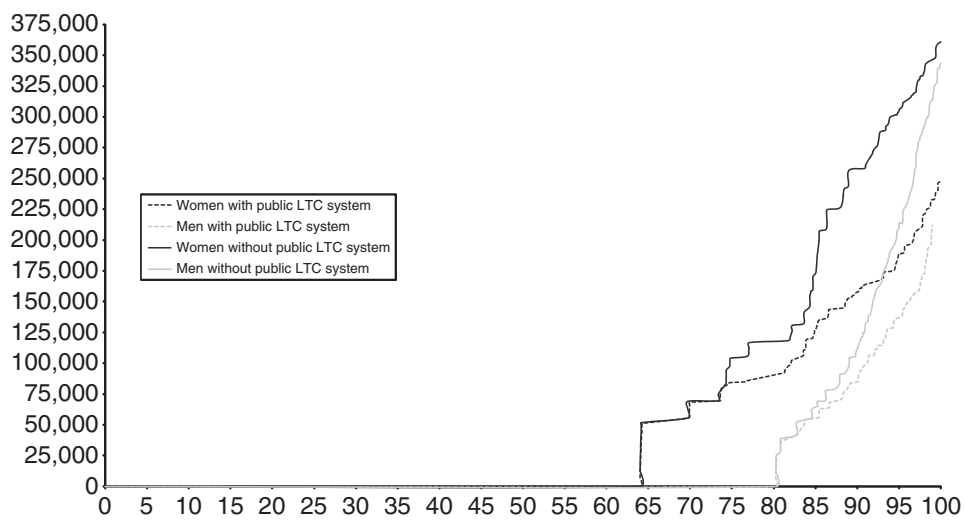

Figure 1. Value-at-Risk for rest of lifetime LTC costs (in Euros) of dependence in Spain for those aged 65 in 2008 with and without LTC public system, by gender.

Note: The $x$-axis shows the percentile probability level and the $y$-axis presents the Value-at-Risk.

Table 2 Risk measures and relative risk mitigation for lifetime LTC costs of dependence in Spain (2008) with and without the public system

\begin{tabular}{|c|c|c|c|c|c|}
\hline \multirow[t]{2}{*}{ Level $(\%)$} & \multicolumn{2}{|c|}{ Value-at-Risk } & \multicolumn{2}{|c|}{ Tail-Value-at-Risk } & \multirow[t]{2}{*}{ Relative Risk Mitigation $\left(R M_{3}\right)$} \\
\hline & Without & With & Without & With & \\
\hline \multicolumn{6}{|c|}{ Men aged 65} \\
\hline 90 & 111.8 & 84.9 & 220.1 & 141.8 & 36 \\
\hline 95 & 210.9 & 136.9 & 277.7 & 175.4 & 37 \\
\hline 99 & 314.6 & 211.8 & 330.6 & 229.4 & 31 \\
\hline \multicolumn{6}{|c|}{ Women aged 65} \\
\hline 90 & 251.2 & 157.8 & 302.4 & 192.0 & 37 \\
\hline 95 & 304.7 & 189.0 & 331.2 & 214.5 & 35 \\
\hline 99 & 346.5 & 232.6 & 353.3 & 330.6 & 31 \\
\hline
\end{tabular}

Cost is expressed in thousand euros. Without the public protection, costs are paid by individuals or their families and with the public system, costs are partly covered by the state. 
The results show that the Spanish public LTC system risk mitigation effect, as measured by $R M_{3}$, exceeds 30 per cent both for men and women at any risk level. In other words, the public system does reduce the risk of very high (or catastrophic) lifetime LTC cost. The introduction of the Spanish LTC public system guarantees that the highest or maximum possible cost incurred by the majority of the population (i.e. 90 per cent or more) is reduced by more than 30 per cent under the public LTC system.

Looking at the most extreme cases, the Tail-Value-at-Risk is also substantially reduced under the current public LTC system. The average lifetime cost for the people who would incur the highest level of expenditure would be much reduced, especially if we look at the highest decile (90 per cent level).

However, the results also show that, despite the risk mitigation offered by the Spanish LTC public system, there is still a risk of about 1 per cent that a man will face lifetime costs of at least $€ 211,800$, and a risk of about 1 per cent that a woman will face lifetime costs of at least $€ 232,600$. This suggests that the risk mitigation offered by the Spanish LTC system may still be too low for the small group of people who face catastrophic costs of care.

\section{Discussion}

\section{Policy considerations}

In the Spanish public LTC system (and other European semi-universal systems), LTC benefits are allocated to people according to severity of need. Benefits cover part of the costs of care. While this system does result in a reduction in the lifetime costs of care faced by all individuals over the care needs eligibility threshold, it is still possible for people to be exposed to catastrophic costs of care if they need care for a long period of time.

If one of the major aims of the LTC system is to mitigate the risk to individuals of facing very high lifetime costs of care, policymakers may need to consider redesigning the way in which benefits are assigned to individuals, so that account is taken of both the severity and the duration of care needs. Policymakers could also consider providing or encouraging additional risk protection designed more specifically to help people who spend a very long period of time requiring care.

In many countries, even if there is a universal public LTC system in place, individuals are expected to make substantial contributions to the costs of their care. ${ }^{21}$ This potentially results in individuals who need care over a long period of time being exposed to very high (or catastrophic) lifetime costs of care. As a result, in Germany, France and Spain private LTC insurance products have been developed with the aim of complementing the public system coverage and providing additional risk mitigation. ${ }^{22}$

\footnotetext{
${ }^{21}$ See, for example, OECD (2011).

${ }^{22}$ Comas-Herrera et al. (2011), Courbage and Roudaut (2008), Guillén and Pinquet (2008), Kessler (2008), Mayhew et al. (2010), Taleyson (2003), Wittenberg et al. (2002) and Zhou-Richter et al. (2010).
} 


\section{Methodological considerations}

The risk mitigation index presented in this paper can be used to assess how much protection is achieved by any one possible scheme (or a combination of schemes) at the individual level. Implementation of the method presented here requires an estimate of the statistical distribution of lifetime LTC costs under the different schemes that need to be compared. There are several approaches to obtain an estimate of the probability distribution function for a given population group, but choosing the best statistical approach among possible methods to obtain the distribution estimates depends substantially on the type of data that is available.

It is very important to check carefully the technical hypotheses that are needed for the selected statistical approximation to the estimation of the distribution function of lifetime LTC costs. In the case study presented above, there is no parametric assumption on the density shape of the random variable that represents lifetime costs, however, several hypotheses were established before obtaining the distribution estimate. When calculating risk mitigation, which requires the comparison of several distribution functions, hypotheses used to approximate those functions need to be consistent along the whole process.

The method presented here can also be used to rank the effectiveness of public LTC protection plans across several countries and additionally, to assess the role of private insurance.

In this note we have only concentrated on the distribution of lifetime expenditure, but costs of protection plans are of crucial importance when ranking those products. The cost of a plan would probably have been paid up front, so including costs in our method would simply imply shifting the distribution of lifetime expenditure, that is, a lump sum should be added to the costs. As a consequence, risk measures considered in this paper would be shifted by a constant equal to the cost of each protection plan, respectively. We leave the question open about a protection that is paid beyond age 65 or the discussion on the cost of compulsory public plans. Moreover, we do not comment on the distribution of terminal wealth, which is much more dependent on individual circumstances.

\section{Acknowledgements}

We are beneficiaries of a financial contribution from the AXA Research Fund as part of "The AXA Research Project on How can private long-term care insurance supplement state systems? The UK as a case study". We thank all team members and specially Adam Steventon for valuable comments. We also acknowledge two anonymous reviewers and the Editor for their valuable help. Part of this research has been sponsored by the Spanish Ministry of Science FEDER grant ECO2010-21787-C03-01.

\section{References}

Artzner, P., Delbaen, F., Elber, J.M. and Heath, D. (1999) 'Coherent measures of risk', Mathematical Finance 9(3): 203-228.

Barr, N. (2010) 'Long-term care: A suitable case for social insurance', Social Policy and Administration 44(4): $359-374$. 
Bolancé, C., Alemany, R. and Guillén, M. (2010) Prediction of the economic cost of individual long-term care in the Spanish population, IREA-Working Papers 201011, University of Barcelona, Research Institute of Applied Economic, revised September 2010, from http://ideas.repec.org/p/xrp/wpaper/xreap2010-08 .html.

Bolancé, C., Alemany, R. and Guillén, M. (2012) 'Efectividad del sistema público de dependencia en España para la reducción del coste individual de cuidados a lo largo de la vida', Revista Economia Aplicada, (forthcoming), Vol. 60.

Coles, S.G. (2001) Introduction to Statistical Modelling of Extreme Values, Berlin: Springer-Verlag.

Comas-Herrera, A., Butterfield, R., Fernández, J.L., Wittenberg, R. and Wiener, J.M. (2011) 'Barriers and opportunities for private long-term care insurance in England: What can we learn from other countries?', in J. Costa-Font and A. McGuire (eds.) Elgar Edward Handbook of Health Policy, Elgar Edward, Cheltenham, UK.

Courbage, C. and Roudaut, N. (2008) 'Empirical evidence on long-term care insurance purchase in France', The Geneva Papers on Risk and Insurance - Issues and Practice 33(4): 645-658.

de Castries, H. (2009) 'Ageing and long-term care: Key challenges in long-term care coverage for public and private systems', The Geneva Papers on Risk and Insurance-Issues and Practice 34(1): 24-34.

Denuit, M., Dhaene, J., Goovaerts, M. and Kaas, R. (2005) Actuarial Theory for Dependent Risks: Measures, Orders and Models, New York: Wiley.

Duffie, D. and Pan, J. (1997) 'An overview of value at risk', Journal of Derivatives 4(3): 7-49.

Fernández, J.L. and Forder, J. (2010) Impact of Changes in Length of Stay on the Demand for Residential Care Services in England, Report commissioned by Bupa Care Services, PSSRU Discussion Paper 2771, Canterbury, UK: PSSRU.

Fernández, J.L. and Forder, J. (2011) Impact of changes in length of stay on the demand for residential care services in England: Estimates from a dynamic microsimulation model, PSSRU Discussion Papers, 2771. PSSRU, London School of Economics and Political Science, London.

Fernández, J.L., Forder, J., Truckeschitz, B., Rokosova, M. and McDaid, D. (2009) How can European states design efficient, equitable and sustainable funding systems for long-term care for older people? Policy Brief 11. World Health Organisation Europe: Copenhagen.

Floreani, A. (2011) 'Risk margin estimation through the cost of capital approach: Some conceptual issues', The Geneva Papers on Risk and Insurance-Issues and Practice 36(2): 226-253.

Guillén, M. and Pinquet, J. (2008) 'Long-term care: Risk description of a Spanish portfolio and economic analysis of the timing of insurance purchase', The Geneva Papers on Risk and Insurance-Issues and Practice 33(4): 659-672.

Jagger, C., Matthews, R., Spiers, N., Brayne, C., Comas-Herrera, A., Robinson, T., Lindesay, J. and Croft, P. (2006) Compression or Expansion of Disability? Forecasting Future Disability Levels under Changing Patterns of Diseases, Annex to the Wanless Social Care Review, London: King's Fund.

Jorion, P. (2007) Value at Risk: The New Benchmark for Managing Financial Risk, 3rd edn., New York: McGraw \& Hill.

Kemper, P., Komisar, H.L. and Alecxih, L. (2005) 'Long-term care over an uncertain future: What can current retirees expect?', Inquiry 42(4): 335-350.

Kessler, D. (2008) 'The long-term care insurance market', The Geneva Papers on Risk and Insurance-Issues and Practice 33(1): 33-40.

Klüppelberg, C., Embrechts, P. and Mikosch, T. (1999) Modelling Extremal Events for Insurance and Finance, Berlin: Springer-Verlag.

Mayhew, L., Karlsson, M. and Rickayzen, B. (2010) 'The role of private finance in paying for long-term care', The Economic Journal 120(548): F478-F504.

McNeil, A.J., Frey, R. and Embrechts, P. (2005) Quantitative Risk Management, Princeton Series in Finance, Princeton: Princeton University Press.

OECD (2011) 'Help wanted? Providing and paying for long-term care, Paris', from http://www.oecd.org/ health/longtermcare and http://www.oecd.org/health/longtermcare/helpwanted.

Panjer, H.H. (2006) Operational Risk: Modeling Analytics, New York: John Wiley \& Sons, Inc.

Panjer, H.H., Klugman, S.A. and Willmot, G.E. (2008) Loss Models: From Data to Decisions, New York: John Wiley \& Sons, Inc.

Pauly, M.V. (1990) 'The rational non-purchase of long-term care insurance', Journal of Political Economy 98(1): 153-168. 
Rodrigues, R. and Schmidt, A. (2010) Paying for long-term care, Policy Brief. European Centre for Social Welfare Policy and Research, Vienna.

Taleyson, L. (2003) Private Long-Term Care Insurance-International Comparisons, Health and Ageing No. 08. The Geneva Association.

Wittenberg, R., Sandhu, B. and Knapp, M. (2002) 'Funding long-term care: The public and private options', Chapter 10, in E. Mosialos, A. Dixon, J. Figueras and J. Kutzin (eds.) Funding Health Care: Options for Europe, pp. 226-249.

Zhou-Richter, T., Browne, M.J. and Gründl, H. (2010) 'Don't they care? Or, are they just unaware? Risk perception and the demand for long-term care insurance', Journal of Risk and Insurance 77(4): 715-747.

Zuchandke, A., Reddemann, S. and Krummaker, S. (2010) 'Impact of the introduction of the social long-term care insurance in Germany on financial security assessment in case of long-term care need', The Geneva Papers on Risk and Insurance - Issues and Practice 35(4): 626-643.

\section{About the Authors}

Montserrat Guillén is Full Professor at the University of Barcelona, Riskcenter. She holds an MSc in Mathematics and a PhD in Economics. She was Visiting Researcher at the University of Texas at Austin and she has also been Visiting Professor at the University of Paris Panthéon-Assas. Guillén was recently awarded the ICREA Academia distinction by the government of Catalonia. In 2011, she was elected president of the European Group of Risk and Insurance Economists.

Adelina Comas-Herrera is Research Fellow at the Personal Social Services Research Unit (PSSRU) of the London School of Economics and Political Science. She has a long list of very significant contributions in leading journals such as Fiscal Studies, Journal of European Social Policy, International Journal of Geriatric Psychiatry, and Ageing and Society, among others. She has been investigating the determinants of future long-term care expenditure, in particular dementia and chronic conditions, both for the U.K. and for other European countries. 